ALPHA No 26 / Julio 2008 (101-117)

ISSN 0716-4254

http://alpha.ulagos.cl

\title{
TRAVESTIR PARA RECLAMAR ESPACIOS: LA SIMULACIÓN SEX-/TEXT-UAL DE PEDRO LEMEBEL Y FRANCISCO CASAS EN LA URBE CHILENA
}

Cross-dress to claim spaces: sex-/text-ual simulation of Pedro Lemebel and Francisco Casas in the Chilean metropolis.

Krzysztof Kulawik*

Resumen

Los textos narrativos de Pedro Lemebel y Francisco Casas - escritores y artistas visuales chilenos contemporáneos- emplean el motivo del travestismo como arma para parodiar y criticar el sistema de valores que determinan el proceso de formación de la identidad, sea individual o social. Utilizando el lenguaje exuberante y ornamentado del estilo neobarroco, estos autores destacan en sus crónicas urbanas y novelas la figura problemática del travesti, un ser andrógino y transgresivo, para proponer una nueva perspectiva hacia las categorías tradicionales de lo masculino, femenino, blanco mestizo y latinoamericano occidental. El uso del artificio lingüístico se asocia, aquí, con la simulación, una técnica artística y discursiva empleada como una máscara que desenmascara la convencionalidad de las categorías que rigen la sociedad patriarcal, masculina-heterosexual y occidental.

Palabras claves: travestismo, identidad, simulación, neobarroco, Chile, ciudad

\begin{abstract}
The narrative texts of contemporary Chilean writer-visual artists Pedro Lemebel and Francisco Casas use the theme of cross-dressing as a weapon to parody and criticize the value system which determines the process of identity formation, both individual and social. Employing the exuberant and ornamental language of the neobaroque style, these authors highlight in their urban chronicles and novels the problematic figure of the cross-dresser, an androgynous and transgressive subject, in order to propose a new perspective toward the traditional categories of masculine / feminine, white / mixed, and Latin American / Western culture. The use of linguistic artifice is associated with simulation, an artistic and discursive technique employed as a mask that unmasks the conventionality of the categories which govern the patriarchal, masculine-heterosexual Western society.
\end{abstract}

Key words: cross-dressing, identity, simulation, neobaroque, Chile, urban

I. En la reciente literatura chilena, el travestismo se ha empleado como una expresión artístico-política de inconformismo y oposición; primero al régimen 


\section{Krzysztof Kulawik}

de Pinochet en los años 1970 y 1980, luego al proceso de la transición democrática neoliberal de los años 1990. El travestismo, a menudo asociado con la homosexualidad, se convirtió en una categoría epistémica opuesta al binarismo heterosexual, sancionado por la tradición patriarcal de la cultura hispánica y occidental, en general. En el represivo contexto cultural de la dictadura - y más tarde de la posdictadura - aparecen narradores como Diamela Eltit y Pedro Lemebel, además de artistas visuales como Juan Dávila, Carlos Leppe y Francisco Casas, quienes, de una manera u otra, hacen referencia al travestismo, empleándolo como un motivo temático estético o como un arma política.

Tal vez, por haber compartido el sofocante entorno político de la dictadura, estos nuevos escritores y artistas por medio del travestismo han procurado "travestir" simbólica y paródicamente el sentido contenido en sus obras, valiéndose de la técnica de la simulación, entendida por Jean Baudrillard como "fingir tener lo que uno no tiene" (1994). Especialmente, Pedro Lemebel y Francisco Casas en sus crónicas y novelas simulan las distinciones convencionales de los géneros, tanto sexuales como artísticos. Con un lenguaje experimental y ambiguos personajes travestis, han perturbado el orden estético establecido por el canon neoliberal-burgués y por su discurso normativo. Como afirma Ben Sifuentes Jáuregui (2002), "transvestism inaugurates an epistemological shift that locates, defines, performs, and erases the fundamental dichotomy: Self / Other. This [. . .] manifests an anxiety that could be called 'the denaturalization of genders"1 Este desplazamiento de categorías se produce en el "hábitat de la pobreza"² y en "el cuarto mundo" urbano (como lo expresa el título de una novela de Eltit), ambos de los que podrían considerarse contextos típicamente latinoamericanos.

Ellis y Abarbaniel (1961) definen el travestismo como deseo y/o acto de vestir ropa del sexo opuesto, palabra procedente del latín trans como “opuesto” y vestis como “vestimenta”, “ropa” (1961: 1012). Según Hogan y Hudson, el travestismo (cross-dressing) se presenta como un fenómeno lúdico de (re)presentación simbólica-externa del sexo opuesto al "biológico", con implicaciones sociales-comunicativas (entre dos sujetos: “yo” y el "otro"), hecha a modo de personificación, actuación , fingimiento o simulación. Puede tener otros fines, como el drag — teatral, humorístico y paródico—; el passing

\footnotetext{
1 “el travestismo inaugura un cambio epistemológico que ubica, define, presenta y borra la dicotomía fundamental de Uno Otro. Esto [ . . .] demuestra una ansiedad que podría ser llamada ‘la desnaturalización de los géneros”. Esta traducción y las siguientes son mías.

${ }^{2}$ Pedro Lemebel. La esquina es mi corazón. Santiago de Chile: Seix Barral, 2001. Citaremos por esta edición.
} 


\section{Travestir para reclamar espacios}

—disfraz y ocultamiento de la verdadera identidad—; el gender-bending — una mezcla indiscriminada de elementos femeninos con masculinos para demostrar su arbitrariedad (159). Por su parte, Randell afirma que, originado en las antiguas saturnalias romanas, hoy el travestismo frecuentemente toma la forma de burla, parodia y juego, particularmente en ocasiones como el carnaval, las fiestas populares u oficiales, y en las artes escénicas, como el performance (actuación/presentación) (1976:51) (51). En el travestir atrae el elemento de ambigüedad, pero no siempre implica una orientación hetero-, homo - o bi-sexual determinada. Añade Randell que no se debe confundir el travestismo con la "transexualidad", o con la inversión del género sexual a la par con una identificación psicosomática completa con el sexo "opuesto" al biológico. Se puntualiza, más bien, su carácter externo, performativo.

Los orígenes del travestismo en la literatura latinoamericana pueden remotarse a la época colonial con las aventuras de Catalina de Erauso, la monja Alférez narrada — entre otros - por Juan Pérez de Montalbán (1784), en las cuales la protagonista, una monja fugitiva, "se cortó el pelo y... empezó a experimentar con su nueva identidad masculina” (2007:12) y se enlistó en el ejército español para ir al Nuevo Mundo con rango de Alférez. Sin embargo, el caso de Catalina no se ajusta del todo a la noción del travestismo actual, ya que obtuvo un permiso oficial del Papa Urbano VIII para continuar vistiendo ropa de hombre (2007:13). Efectivamente, será bastante más tarde, en las extravagancias de los poetas modernistas, como los del uruguayo Julio Herrera y Reissig o del colombiano Porfirio Barba Jacob cuando el travestismo emerge como un comportamiento consciente con valor estético. Ya más recientemente, la figura del travesti está presente en narradores y poetas cubanos como José Lezama Lima, Severo Sarduy y Reynaldo Arenas, y en algunos cuentos tempranos del chileno José Donoso.

En el contexto del Chile posgolpe militar de 1973, y de fines de los setenta, emergieron grupos artísticos radicales como el CADA (Colectivo de Acciones de Arte) grupo constituido por los artistas visuales Lotty Rosenfeld y Juan Castillo, el poeta Raúl Zurita, la novelista Diamela Eltit, entre otros (Brito, 1990:26). Posteriormente, en la literatura producida durante la transición democrática de los noventa, continuaron escribiendo la novelista Diamela Eltit, la crítica Nelly Richard y el cronista Pedro Lemebel que había emergido, por primera vez, del grupo de artistas y escritores homosexualestravestis activos en Santiago a finales de los años setenta. Lemebel participó, inicialmente, en el Taller Literario de Pía Barros a partir de lo cual publicó Los incontables (1986) su primer libro de cuentos eróticos. Francisco Casas, se dio a conocer, en 1987, como cofundador del colectivo de arte visual "Las Yeguas del Apocalipsis” y desarrolló con Lemebel trabajos transgresivos en instalaciones y performance desde los últimos años del gobierno de Pinochet 


\section{Krzysztof Kulawik}

hasta aproximadamente 1992, asombrando al público santiaguino con sus actuaciones osadas y sexualmente explícitas. Entre 1995 y 2001, Lemebel incursiona en el género de la crónica urbana con La esquina es mi corazón, Loco afán y De perlas y cicatrices, Tengo miedo torero. Por su parte, Francisco Casas logra reunir sus recuerdos de la actividad artística con Lemebel en el proyecto "Las Yeguas del Apocalipsis" en su seudonovela (o crónica ficcionalizada) Yo, yegua (2004).

En sus obras, Lemebel y Casas emplean voces narrativas en primera persona, además de elementos autobiográficos, para aparentar una presencia intratextual. Lemebel con la voz de un narrador homodiegético en La esquina es mi corazón (1995) y Casas con las voces de sus alteregos narrativos (homo o heterodiegéticas) de Dolores del Río y María Félix en Yo yegua, haciendo alusión paródica a las cantantes clásicas de rancheras mexicanas. Los personajes-narradores recorren la ciudad sitiada por el control dictatorial, presenciando y revelando espacios de disensión: happenings, performances, cines, librerías, manifestaciones políticas, parques, y "callampas" santiaguinas. La exuberante representación textual de la ciudad por medio del lenguaje figurativo, ornamental y artificioso crea un efecto simulador, el de una narrativa lúdica y paródica, pero, además, los textos de Casas y Lemebel proponen un nuevo discurso fragmentado, alternativo al tradicional, al utilizar el travestismo como una postura artística y política radical para descentrar nociones de la identidad, no solamente sexual, sino nacional, étnica y cultural. La figura del travesti puede representar aquí una ruptura con el sujeto masculino heterosexual — chileno y blanco - representativo de la cultura oficial. En estas narrativas, la referencia a esta ruptura se efectúa por medio de la apropiación simbólica y del reclamo de espacios de una ciudad en decadencia por medio de su recreación literaria. La urbe sirve de marco a la acción narrativa; un marco no sólo externo-documental sino interno-simbólico y textual. La inestabilidad y movilidad del espacio urbano llega a ser funcional, y convierte el texto en un "espacio cómplice" para la transformación de los personajes, sus apariencias y actuaciones. Se simula una ciudad moderna y desarrollada, se simulan los roles sexuales masculinos y femeninos, todo desde una perspectiva travesti. Esta simulación se realiza a través del artificio lingüístico y narrativo, la experimentación con el lenguaje y la parodia. Para efectos de esta simbolización del espacio urbano, se recurre a la simulación textual, centrada en las actuaciones de los travestis y realizada por medio de un lenguaje artificioso.

II. La presencia travesti se observa, ya, a partir de los elementos externos del texto, lo "paratextual" en términos de Genette. En la carátula de $L a$ esquina es mi corazón —una foto-instalación realizada por Pedro Marinello- 


\section{Travestir para reclamar espacios}

aparece la foto de Lemebel travestido y posando semiacostado con un lagarto en el regazo. En Yo, yegua, la carátula contiene una foto de una de las performances más famosas de las "Yeguas del Apocalipsis" que presenta a Casas y a Lemebel cabalgando desnudos por las calles de Santiago. A partir de estas portadas se destacan los autores-protagonistas travestis, cuyas voces, miradas y acciones adopta el narrador textual. Este narrador a veces es el homodiegético ("yo"), otras veces es un heterodiegético y omnisciente ("él”), que adopta la voz colectiva en tercera persona del "hábitat de la pobreza", la "herencia neo-liberal de esta demos-gracia [. . .] carne de cañón en el tráfico de las grandes políticas”, “desecho sudamericano” (35-36) de la gran urbe que es Santiago de Chile con todos sus contrastes. El espacio de la acción y de la enunciación discursiva hace referencia a lugares que existen extratextualmente y cuya existencia puede comprobarse en un mapa: el Parque Forestal, la Plaza Italia, el cine Nagasaki, la Alameda; varios barrios como La Florida, Brasil, San Miguel. No obstante, estos sitios adquieren una función simbólica dentro del texto como operaciones de memoria asociada con actos transgresivos. La imagen de la ciudad que se presenta en las crónicas es borrosa, móvil, irregular y fracturada. En entrevista con Jeftanovic, Lemebel la llamó "una territorialidad movediza, también tránsfuga” (2000:74), describiéndola en su crónica como una "radiografía obscena del álbum familiar, o complicidad de pasiones [. . .] como flujos que permean el libre cauce metropolitano" (49). Son pasiones que miran, según Casas “[. . .] entre las grietas de la ciudad destruida por el bombardeo [del golpe militar de Pinochet]". ${ }^{3}$ El texto de Casas conforma una serie de contrastes, típicos de todas las urbes latinoamericanas: con imágenes excesivamente ornamentadas $\mathrm{y}$, a la vez, abyectas; con un vocabulario rebuscado, y a la vez, vulgar; con una sintaxis elaborada y artificiosa, combinada con otra simple, oral y callejera. El relato testimonial se convierte en una irónica y burlesca performance textual de denuncia, hecho desde una perspectiva queer, trazado como una cartografía urbana "loca" por un travesti con rasgos transitivos y transexuales. Irónicamente, constituye una especie de escritura "ciudad-anal" del "ver-el-ano" santiaguino; [juego de palabras del autor], una escritura radicalmente subversiva por hablar de los callados quehaceres callejeros de los homosexuales travestidos; de los pandilleros, drogadictos, voyeurs, todos participantes de la desequilibrada bonanza de la comercialización neoliberal global, de una política de consumo urbano.

En la esquina es mi corazón, la tensión aumenta al presentarse contrastes descritos con un lenguaje elaborado y figurativo que está en

\footnotetext{
${ }^{3}$ Francisco Casas. Yo, Yegua. Santiago de Chile: Seix Barral/Planeta, 2004, 21. Citaremos por esta edición.
} 


\section{Krzysztof Kulawik}

disonancia con el objeto abyecto de la descripción de Lemebel: "La ciudad estalla en una megalópolis apresurada para el sopor de estos paquidermos [aquí los autobuses], que se alejan de la urbe tosiendo sus vapores mortíferos” (146). Esta descripción contrasta con la imagen de la ciudad decorada para la Navidad: "el sonajeo de campanas y relumbros dorados, la noche buena estalla en voladores de luces y cometas de fósforo que iluminan la ciudad como una pequeña vía láctea enredada en las crestas de los cerros [andinos]. Así la urbe al fogonazo de diciembre se traviste de esquimal navideño [. . .] Mucho brillo y collares de luces para decorar el semblante mugroso de los edificios” (147). Para destacar más el contraste entre el brillo y el lujo que encubren el deterioro de los edificios y las esquinas, leemos en Casas

Yo vengo del final de la calle. Calle sin salida. El mismo lugar donde en invierno se estanca el aguacero transformando el resentido lugar en un pantano televisivo. Barro y agua producen en las noches de julio [invierno] un extraño set. Un río miserable navegando en botes de goma por camarógrafos iridiscentes que [. . .] transmiten al país la tragedia [. . . ] la confusión de la montonera de cuerpos que la pobreza incestuosa amontona como a perros en chozas cubiertas por cartones negros (14-15).

Con frecuencia se presentan imágenes de la marginal periferia santiaguina: "[. . .] en las cercanías se fueron instalando tomas de terrenos ilegales de miles de familias sin vivienda, procedentes de la cordillera de la Costa. Las chozas de cartón proliferaron como callampas” (150).

Por otro lado, la barata abundancia material del sistema comercial neoliberal —introducido por la política de Pinochet y sus “Chicago Boys”, y continuado en la transición democrática en los años noventa - inunda la ciudad con la oferta "libre” y masiva de baratijas y de fáciles placeres eróticos pagados. Esto se reproduce a modo de un exceso en el exuberante discurso barroquizante - por figurativo y sonoro- de las crónicas de Lemebel y de la novela de Casas. En este contexto urbano, las esquinas están pobladas por figuras de travestis que se deslizan por las calles censuradas por el aparato vigilante. En Lemebel leemos: "Por eso cada noche cruza el enramaje de sus plumas y no le importa coagularse con otros hombres, que serpentean los senderos como anacondas perdidas, como serpientes de cabezas rojas que se reconocen por el semáforo urgido de sus rubíes” (24-25). En Casas, vemos representadas con el mismo esplendor poético de tinte barroco "[. . .] escenas de pajarracos copulando, tucanes esbeltos haciendo trinar la glorieta resplandeciente de esa Fontana de Trevi hundida” (24). Pero, Casas da un paso más al establecer un diálogo intertextual con Cervantes, mediante alusiones textuales a Don Quijote de la Mancha que podrían ser indicio de un 


\section{Travestir para reclamar espacios}

carácter paródico: "Putos de adargas antiguas y lanzas en astillero desmembrando la opacidad cínica "del puente a la Alameda que menudo pie las lleva” (24). Ahora bien, si abrimos el Capítulo Primero de la Primera Parte de la obra cervantina, leemos que "[. . .] no ha mucho tiempo que vivía un hidalgo de los de lanza en astillero, adarga antigua, rocín flaco, galgo corredor". El tono paródico de Yo, yegua, se aumentaría mediante la presencia común de "las yeguas" provocadora ante el (los travestis María Félix y Dolores del Río) caballo de Don Quijote: que permite observar como "[ . . . ] a Rocinante le vino en deseo de refocilarse con las señoras flacas" para luego ser derribado con una tremenda paliza por parte de unos pastores gallegos (148). Observamos un paralelismo paródico entre las ocurrencias de los personajes cervantinos y los vagabundeos de las dos “yeguas" por las calles de Santiago en busca de aventuras amorosas.

En cuanto al espacio burdo de la ciudad, en Yo, Yegua se transforma simbólica y figurativamente - con lenguaje opulento- en un espacio mítico, de deseo erótico con rasgos clásicos y mitológicos, como en la escena del encuentro de los protagonistas a orillas del río

Dolores del Río y María Félix se pasan las tardes recostadas en uno de los escaños que reposan junto a la afrancesada ribera sur del río Mapocho. Al verlas a la distancia, semejan Cleopatras perversas junto a un Nilo obsesivo, por cuyo torrente blasfeman flamencos rosas el sueño de Anubis. En la borrachera ven navegar cauce abajo la inigualable galera del César. Las remilgadas ven las piernas del joven emperador decoradas con un montículo eréctil que las estremece (18).

Se puede observar en la cita, cómo el uso del lenguaje figurativo y ornamentado de Casas transforma el espacio urbano de algo abyecto en algo pretendidamente poético. De semejante manera, la violencia callejera se sublima en el uso del "copihue” rojo, como símbolo y en la aliteración onomatopéyica de sonidos velares oclusivos [k]: "conteniendo el vómito de copihues lo coquetea" (167). La sangrienta escena final, en la cual la "loca" drag queen termina apuñalada, se sublima por el uso del lenguaje figurativo: "La noche del erial es entonces raso de lid, pañoleta de un coliseo que en vuelo flamenco la escarlata. Espumas rojas de maricón que lo andaluzan flameando en el tajo. Torero topacio es el chico poblador que lo parte, lo azucena en la pana hirviendo, trozada Macarena” (167).

Por su parte, la crónica de Lemebel muestra una voz narrativa que se traslada desde su posición externa heterodiegética en tercera persona y con

${ }^{4}$ Miguel de Cervantes. Don Quijote de la Mancha. Edición, introducción y notas de Martín de Riquer. Barcelona: Planeta, 1994. 


\section{Krzysztof Kulawik}

discurso indirecto, a una homodiegética (en primera persona y con discurso directo) para identificarse más con otros personajes. Se funde con ellos y asume su punto de vista, como se observa en el siguiente fragmento: "La loca sabe el final de esas aventuras, presiente que el después deviene fatal, sobre todo esta noche cargada al reviente [. . . ] la excita ese olor a ultraje [. . .]. Esas ganas de no sé qué. Ay [. . .] esa histeria anal [. . .] Ay ese fragor” (162. Subrayado mío). Otras veces, el narrador se revela en primera persona como un personaje, como una voz que de repente deambula entre la multitud del barrio: "Dedicado a los chicos del bloque, desaguando la borrachera en la misma escala donde sus padres beatlemaníacos me hicieron a lo perrito” (29). A lo largo de las crónicas, esta fluctuante voz narrativa de un guía-observador (un voyeur) ofrece una pluralidad de focos y una polifonía de voces que se originan en la urbe polifacética.

Para Lemebel el impacto de la descontrolada comercialización urbana se ve en las "toneladas de mugres japonesas destinadas al mercado del encanto" (154), en "La sobreabundancia de productos choca con el abandono, el desecho del producto consumido, improductivo y rechazado en un implacable sistema de libre oferta y demanda, de despilfarro, de la sobrevivencia del más fuerte”. Lemebel asume, aquí, una clara voz que denuncia un sistema que no perdona ni tiene en cuenta al más débil, al marginal

Sitios baldíos que la urbe va desmantelando para instalar nuevas construcciones en los rescoldos del crimen. Teatros lúgubres donde la violencia contra homosexuales excede la simple riña, la venganza o el robo. Carnicerías del resentimiento social que se cobran en el pellejo más débil, el más expuesto" (168-69). "Parecieran inútiles los detergentes y su alba propaganda feliz, inútil el refregado, inútiles los sueños profesionales o universitarios para estos péndex de última fila [. . . ] Herencia neoliberal o futuro despegue capitalista en la economía de esta 'demos-gracia” (35).

Para Casas, la presencia ambigua de los travestis - por simulada y camaleónica- se vuelve más conspicua en el espacio físico de la ciudad: en los interiores de los ilusorios cafés — como el Jaque Mate frecuentados por los activistas de izquierda:

La luz blanquea los múltiples maquillajes de la noche, gesticulando la convivencia acicalada. La perversión de la pose. La barra y las mesas están repletas. Bandas de rock y oscuras estrellas trans entorpecen la entrada al baño. Dentro del pequeño cuarto, la mierda se rebalsa de la taza. Apiladas alrededor del único urinario, como reinas magas junto al 


\section{Travestir para reclamar espacios}

pesebre, las locas hacen su agosto" (126). [. . .] Estos seres trastornados han sido su familia durante todos los años del sitio de la ciudad prohibida. Degenerados, deformados por la fogosidad del licor y la comida descompuesta, la que luego de ingerir vomitan bajo las mesas (128). En todo el grotesco escenario del local, los sexos cambian y se confunden de modo que no sólo los hombres se travisten, sino también las mujeres se visten de hombres: "Josefa Ruiz vestida de hombre se ha pintado un pequeño mostacho, disputándole a Marco Enríquez los seductores movimientos de Dolores" (133).

Con sus osadas incursiones paródicas de los performance, las travestidas "Yeguas del Apocalipsis" se toman las calles y otros lugares públicos de Santiago, sitiados aún por el control militar de fines de los 80 . Entran sin invitación en los eventos poéticos, culturales y políticos, como en la Feria del Libro del Parque Forestal; en el homenaje a Raúl Zurita en La Chascona de Neruda; en la celebración high life de un 14 de julio en la Alianza Francesa en el nuevo y remodelado Centro Cultural de la Estación Mapocho; en las proclamaciones del nuevo presidente, Patricio Aylwin; en la Comisión Chilena de los Derechos Humanos pero, sobre todo, en la famosa cabalgata por las calles de Santiago hacia la Facultad de Arte de la Universidad de Chile, cuando los dos artistas montan desnudos. Su presencia hace un fuerte contraste con las simultáneas manifestaciones estudiantiles, reprimidas por el régimen, según describe Casas

La lluvia de papel, seguido de aplausos secos, cae sobre los cuerpos desnudos de María Félix y Dolores del Río. Las ladys Godivas van montadas sobre la yegua Parecía. Dolores gobierna el freno [. . .] María tomada de la cintura de Dolores, acomoda las nalgas en la ancha grupa de la bestia de tiro, que avanza grácil, trotando como si llevara un atado fresco de lechugas costinas. Varios días llevan las violentas protestas de los estudiantes exigiendo la renuncia del rector militar. Vociferan en todo el territorio chileno el retorno del país a la democracia. Las manifestaciones dejan cientos de estudiantes heridos, la policía antimotines les hace frente con bombas lacrimógenas y carros lanza-agua (167).

La presencia travesti en el contexto de la ciudad sitiada por el régimen reclama un espacio propio. Lo hace al apropiarse del espacio público — de la calle- con este desfile de sus cuerpos desnudos. La ostentosa, escandalosa y artificial presencia de las locas; esta simulación sexual entre lo masculino y femenino; esta extravagancia de poses y actos, se expresa en el texto con exuberancia lingüística, con artificio, que le da un tono poético, barroco y 


\section{Krzysztof Kulawik}

decadente a las dos obras en cuestión. Observemos este otro fragmento de Yo yegua:

María Félix, fumando de una larga boquilla de carey, lleva puesto un vestido futurista, largo, de terciopelo rojo. Sobre su cabeza parece volar un faisán disecado - con las alas distendidas - el que en medio del delirio de una descomunal competencia fashion se puso en la testa a modo de sombrero (186).

III. Jean Baudrillard, en Simulacres et simulation (1994) afirma: "To dissimulate is to pretend not to have what one has. To simulate is to feign to have what one doesn't have. One implies a presence, the other an absence". 5 En el caso de Lemebel y Casas, el artificio, empleado como juego de apariencias travestis y su exuberante representación textual, tiene como fin la disimulación de una apariencia "natural” (masculina) y la simulación de una diferencia equívoca (femenina) como lo es la exteriorización convencional del género sexual (sea femenino o masculino) en la sociedad occidental. El artificio simula ser uno en la otredad (porque realmente no hay otro) y simula la inadvertida presencia del otro en uno (porque no hay uno). La convención de la diferenciación sexual juega una parte clave como modelo (artificial, por convencional) que se impone y precede a la tradición, modelo copiado y parodiado en las crónicas de Lemebel. Continúa afirmando Baudrillard que "Simulation is characterized by a precession of the model, of all the models based on the merest fact the models come first [. . .]. This anticipation, this precession, this short circuit, this confusion of the fact with its model is what allows each time for all possible interpretations, even the most contradictory, all true" ${ }^{\prime 6}$ (1994:16-17.Subrayado en el original).

Como efecto, se produce en el texto la ambigüedad, lo equívoco; el descentramiento de la regla convencional, de la ley impuesta por el poder patriarcal. El texto lúdico se vuelve satírico y rebelde, contestatario de la tradición.

Las técnicas de simular la sexualidad incluyen la acumulación de detalles de vestimenta y la representación del comportamiento excéntrico de los personajes. Frecuentemente, la simulación se produce como ocultamiento o transformación del aspecto físico de los personajes travestis en la trama;

\footnotetext{
5 "Disimular es fingir no tener lo que uno tiene. Simular es fingir tener lo que uno no tiene. El uno implica una presencia, el otro una ausencia”.

6 "La simulación se caracteriza por una anticipación del modelo, de todos los modelos basados en el hecho más simple de que los modelos vienen primero [. . .] Esta anticipación, este cortocircuito, esta confusión del hecho con su modelo es lo que permite cada vez todas las interpretaciones posibles, aun las más contradictorias, todas acertadas”.
} 


\section{Travestir para reclamar espacios}

también en el discurso narrativo se esconde la identidad del narrador fluctuante tras atributos sexuales de índole ambigua. Al observar la exuberancia del lenguaje, visible en la superficie textual de las obras, puede hacerse una analogía con el concepto de la "máscara textual" simuladora que es la escritura misma. Como explica Severo Sarduy, la máscara es la exterioridad aparente del texto; la superficie que nos engaña porque no hay nada detrás de la superficie de la máscara. Ésta sólo se esconde a sí misma y nos hace suponer que es la esencia, la sustancia misma (1990:224).

Sarduy establece una relación entre el acto de la escritura como simulación (la manera de travestir "un” sentido con palabras) y el disfraz (externo) que hace de su sexualidad un travesti, transgrediendo las distinciones de los rasgos de los dos sexos establecidos según patrones binarios preestablecidos. El travestismo llega a ser una metáfora para lo que es la escritura en sí, un acto de simular en la coexistencia, en el mismo cuerpo, de significantes masculinos y femeninos antagónicos (1990:224).

A la transformación de apariencias sexuales se suma la pulsión que tiende a la transformación total del sujeto en otro ser distinto: el proceso de la metamorfosis. El travestismo, como una forma de metamorfosis, sería el ejemplo más claro de la utilización transformadora del cuerpo y del espacio que ocupa éste, siempre con fines políticos. Pero, como otra vez lo señala Sarduy, en esta transformación no se trata meramente de una copia mimética de un modelo para aparentarse/apoderarse de él, sino de transgredir los límites que el modelo impone hasta des-naturalizarlo, paródicamente, en las bases de su existencia, desnudando las convenciones que lo rigen. Acaso ¿̇significa una forma de reclamar un espacio — el local, la calle, la página — como en el caso de las crónicas de Lemebel y Casas? Consideremos la siguiente afirmación de Sarduy

El travesti humano es la aparición imaginaria y la convergencia de las tres posibilidades del mimetismo. El travestimiento, propiamente dicho, impreso en la pulsión ilimitada de metamorfosis, de transformación, no se reduce a la imitación de un modelo real, determinado, sino que se precipita en la persecución de una irrealidad infinita y, desde el inicio del "juego" aceptado como tal, irrealidad cada vez más huidiza e inalcanzable, ser cada vez más mujer, hasta sobrepasar el límite, yendo más allá de la mujer [.. . ] (1982: 56).

IV. El elaborado lenguaje poético de los textos analizados está en disonancia con el crudo contenido de estas obras que exponen la situación socioeconómica de Santiago de Chile, una ciudad llena de contrastes. Las técnicas narrativas y elementos de estilo y de lenguaje tan contrastantes son propios de lo que algunos críticos como Sarduy, Gálvez Acero, Bustillo y Ortega ya 


\section{Krzysztof Kulawik}

habían llamado el "estilo neobarroco”, el cual —por medio de la técnica de la simulación - funciona, aquí, como una forma de reclamar el espacio público y como una estrategia de crítica social. Desde el espacio textual, el discurso neobarroco adquiere un significado político radical en el espacio urbano postmoderno (de una ciudad llena de contrastes incongruentes). Constituye una voz artística excesivamente elaborada, una voz que representa un entorno urbano decadente.

En La esquina es mi corazón de Lemebel y en Yo, yegua de Casas, el travestismo se adopta como una estrategia formativa de una identidad descentrada e híbrida con toda la transitividad de atributos masculinos y femeninos inestables. En palabras de Gilles Deleuze (1977), la identidad travesti sería un "devenir minoritario" que se basa en una relación de multiplicidad transitiva, de pasar "entre" todo dualismo (8, 40-43). La aproximación de Lemebel al tema del travestismo coincide con la de Sarduy. Haciendo hincapié en la relación entre la esfera personal y la pública, Sandra Garabato (2003) afirma que en los dos autores hay "una relación entre travestismo y subversión que se extiende más allá de las leyes de la sexualidad para ubicarse en el terreno de las afiliaciones económicas y políticas” (49). Garabato sigue observando que los dos autores comparten una actitud antipatriarcal y antifalocéntrica, la cual se traduce en una transgresión por medio del uso de una lengua exuberante, ornamentada y experimental; una lengua que simula. El uso lingüístico desbordante se vuelve una herramienta de denuncia al no limitarse a la función meramente comunicativa del lenguaje. La inusitada combinación de técnicas estilísticas, simuladoras del sentido, tales como la acumulación de metáforas, la experimentación lingüística, la parodia, todas características del barroco histórico, pero con un contenido nuevo, poblado de imágenes de tecnología, comercio y moda - $\mathrm{y}$ de seres sexualmente ambiguos - produce un efecto desestabilizador y desconcertante. Éste es el propósito principal del llamado "neobarroco", definido hace ya varias décadas por Sarduy como un estilo radical y contestatario del orden económico burgués capitalista, de la "administración tacaña de los bienes” (1987: 209). El neobarroco desestabiliza en el nivel del lenguaje, en la base estructural misma de todo funcionamiento de este orden burgués: patriarcal, logocéntrico y heterosexual.

El interés simultáneo de estos artistas por el lenguaje y por la sexualidad es más que una coincidencia resultante de un juego experimental. Es una exploración consciente de las posibilidades discursivas de construir una identidad sexual transitiva y múltiple, alternativa al binarismo heterosexual impuesto por el canon cultural occidental. Usan técnicas alternativas y géneros artísticos mixtos: el performance, el happening, la instalación, el video, la fotografía, la pintura, el ensayo crítico, la crónica 


\section{Travestir para reclamar espacios}

ficcionalizada, la novela experimental. Las obras de los autores travestis chilenos, que en palabras de Efraín Barradas también hacen "una relectura de la tradición desde la perspectiva kitsch y camp" (2000), pretenden desenmascarar y transgredir la sexualidad binaria de los sujetos para revelar la arbitrariedad de los géneros como construcciones lingüísticas, culturales, y paródicamente, desnudar los propios mecanismos que los conforman.

La neobarroca "cartografía loca" de la urbe chilena que ofrecen Lemebel y Casas es comparable con las obras de otros ensayistas-cronistas urbanos latinoamericanos de fines del siglo XX como las del argentino Néstor Perlongher (Bianchi, 139); del mexicano Carlos Monsiváis y del puertorriqueño Edgardo Rodríguez Juliá. ¿Es sustentable hablar aquí de un "neobarroco translatinoamericano"? Ángeles Mateo del Pino apunta hacia la capacidad abarcadora del ojo crítico de los autores chilenos travestis y su proyección desde lo particular y local —Santiago - hacia lo universal, de modo tan característicamente postmoderno. Mateo del Pino se refiere a las crónicas de La esquina es mi corazón como "una macrocrítica social, un puzzle de historias que ofrecen una panorámica del espíritu que planea hoy por la ciudad de Santiago. Tienen, a su vez, el don de reflejar el ánimo que sobrevuela por todas las grandes urbes. De ahí que uno de los aciertos de estas crónicas sea el hecho de que, instalándose en lo particular local, construyan una visión de lo universal” (1998: 23).

La imagen de Santiago, una ciudad hipercomercializada y fragmentada, se crea en las crónicas de Lemebel desde una perspectiva queer, del "otro": el ser marginado, el homosexual y el travesti como ser transgresivo y subversivo del orden neoliberal capitalista, patriarcal y falo(-go-)céntrico. Se presenta, así, para polemizar las definiciones de la nacionalidad chilena, la etnicidad hispana, latinoamericana, etc., a partir de la sexualidad que se realiza en el espacio textual de la crónica urbana. La figura del "otro" sexual/étnico está disimulada tras un telón espesamente bordado, ornamentado/otramentado con lenguaje exuberante. Se ubica al nivel de "lo que el texto no quiere decir y dice” en palabras de Dino Plaza Atenas, y "da cuenta del funcionamiento de la différance descrito por Derrida [. . .] al conseguir el autor que sus crónicas hablen con el lenguaje del Otro y para el Otro sobre lo marginal” (1999: 134). También, a modo del "suplemento" derrideano, se presenta como una visión "rara”, o queer, de una metrópoli latinoamericana.

En suma, el discurso travesti de la neovanguardia chilena constituye una propuesta radical para reconceptualizar, de modo más inclusivo, la identidad sexual, étnica y cultural latinoamericana. Esta neovanguardia usa el travestismo en el espacio urbano chileno como su marco de actuación y de apropiación, como su escenario simbólico. Este marco no se encuentra solamente fuera del texto, como un mero referente extratextual o como un 


\section{Krzysztof Kulawik}

fondo para la actuación excéntrica de las "locas", sino que se presenta como un elemento simbólico integrado como parte del mensaje subversivo. No se trata solamente de un telón de fondo "real" (extratextual), sino que funciona como un metadiscurso, o un "hiperdiscurso", siguiendo la nomenclatura de Baudrillard referente a una "hiperrealidad", consciente de su condición simuladora en toda representación. En los textos analizados, se confirman las palabras de Baudrillard al respecto: "Such is simulation, insofar as it is opposed to representation. [. . .] Whereas representation attempts to absorb simulation by interpreting it as a false representation, simulation envelops the whole edifice of representation itself, as a simulacrum"7. En la representación (artística/literaria) hay máscaras. Nada más. Y nada detrás de ellas. Todo es simulación, juego de apariencias que delata el contenido ficticio (y vacío) de las convenciones que conforman la identidad sexual, nacional, étnica, etc., y las que sostienen el poder patriarcal, heterosexual, blanco y occidental. El discurso del travesti chileno — que además de ser “indio" es "mestizo", como resalta en entrevista con Blanco y Gelpi 96- y latinoamericano amenaza el orden burgués establecido y entra en los espacios del "entre" los elementos binarios (blanco-moreno, hombre-mujer, etc.) que componen el sistema social y político impuesto. Tal discurso entra y abre nuevos ámbitos en las fisuras del viejo orden y del discurso cultural tradicional.

Con todo, las obras de Lemebel y Casas constituyen una propuesta crítica para la inclusión de voces marginales y descentralizadoras en la discusión postmoderna sobre las relaciones entre la identidad sexual, el poder político y la expresión cultural en el contexto latinoamericano de los comienzos del siglo XXI.

Central Michigan University* Department of Foreign Languages Literatures \& Cultures Pearce Hall 322·Mount Pleasant Michigan 48859 (EUA) k.kulawik@cmich.edu

\footnotetext{
7 Así es la simulación, en la medida en que se opone a la representación. Mientras la representación intenta absorber la simulación interpretándola como una falsa representación, la simulación envuelve toda la estructura de la representación misma como un simulacro.
} 
Travestir para reclamar espacios

\section{BIBLIOGRAFÍA}

ALARCÓN NEGY, Alma Margarita. "El texto narrativo homoerótico hispanoamericano en Arenas, Lemebel, Manrique y Pérez" (Tesis doctoral). University of Houston, agosto 2002.

BARRADAS, Efraín. "Para travestir mejor: Pedro Lemebel y una lectura política: el canon desde los "márgenes". The Bacardi Eminent Scholar Lecture Series. University of Florida (Dec. 6), 2000. Apuntes de una presentación oral. No hay paginación.

BAUDRILLARD, Jean. Simulacra and Simulation. Tran. by Sheila Faria Glaser. Ann Arbor: University of Michigan P., 1994.

BIANCHI, Soledad. "La esquina es mi corazón. Pedro Lemebel”, en Hispania. 74 (1996): 137-39.

BLANCO, Fernando A. (ed.). Reinas de otro cielo. Modernidad y autoritarismo en la obra de Pedro Lemebel. Santiago de Chile: LOM, 2004.

BLANCO, Fernando y Juan Gelpi. "El desliz que desafía otros recorridos: entrevista con Pedro Lemebel”. Nómada: creación, teoría, crítica. 3 (1997): 93-98.

BRITO, Eugenia. Campos minados. Santiago de Chile: Cuarto Propio, 1990.

BUSTILLO, Carmen. Barroco y América Latina: un itinerario inconcluso. Caracas: Monte Ávila, 1990.

CAMACHO PLATERO, Luzmila. La Monja Alférez de Juan Pérez de Montalbán. Newark, Delaware: Juan de la Cuesta, 2007.

CASAS, Francisco. Yo, yegua. Santiago de Chile: Seix Barral/Planeta, 2004.

CERVANTES, Miguel de. Don Quijote de la Mancha. Edición, introducción y notas de Martín de Riquer. Barcelona: Planeta, 1994.

DELEUZE, Gilles y Claire Parnet. Dialogues. Paris: Flammarion, 1977.

DERRIDA, Jacques. La dissémination. Paris: du Seuil, 1972.

------ De la grammatologie. Paris: du Seuil, 1976.

ELLIS, Albert and Albert Abarbaniel. The Encyclopedia of Social Behavior. Vols. 1, 2. New York: Hawthorn Books, 1961.

ELTIT, Diamela. El cuarto mundo. Santiago de Chile: Planeta, 1988.

ESCOBAR, Leonardo. "Yo, barroco”. (Abril) 2004. Crítica. 17 (junio), 2006. http://www.critica.cl/html/escobar_01.htm

ESPINOZA, Patricia. "Un mapa de la denuncia: entrevista con P. Lemebel”. Letras (2002): 1-2. May 19, 2002

$<$ http://www.letras.s5.com/lemebel.htm>.

GÁLVEZ ACERO, Marina. La novela hispanoamericana contemporánea. Madrid: Taurus, 1987. 
Krzysztof Kulawik

GARABATO, Sandra. "Lemebel: políticas de consenso, masculinidad y travestismo”. Chasqui 32. 1 (2003): 47-55.

GENETTE, Gérard. Figures III. Paris: Seuil, 1972.

GUERRA CUNNINGHAM, Lucía. "Ciudad neoliberal y los devenires de la homosexualidad en las crónicas urbanas de Pedro Lemebel”. Revista Chilena de Literatura 56 (2000): 71-92.

HOGAN, Steve and Lee Hudson. Completely Queer: The Gay and Lesbian Encyclopedia. New York: Henry Holt, 1998.

JEFTANOVIC, Andrea. "El cronista de los márgenes. Entrevista con Pedro Lemebel”. Lucero 11.2 (2000): 74-78.

LANZA LOBO, Cecilia. Crónicas de la identidad: Jaime Sáenz, Carlos Monsiváis y Pedro Lemebel. Quito: Universidad Andina, 2004.

LEMEBEL, Pedro. La esquina es mi corazón. (1995) Santiago de Chile: Seix Barral. Biblioteca Breve, 2001.

------- Loco afán: crónicas de sidario. Santiago de Chile: Planeta, 1996.

LOLAS, Jazmín. "Ex integrante de la famosa dupla, publica su primera novela”. Las últimas noticias. (5 dic. 2005). 10 junio, 2006. www.lun.com.

MASIELLO, Francine. The Art of Transition. Latin American Culture and Neoliberal Crisis. Durham, London: Duke UP, 2001.

MOLLOY, Sylvia and Robert McKee Irwin, (eds.). Hispanisms and Homosexualities. Durham and London: Duke UP, 1998.

OLEA, Raquel. "De la épica lumpen al texto sudaca: la narrativa de Diamela Eltit”, en Albricia: la novela chilena del fin de siglo Ed. Verónica Cortínez. Santiago de Chile: Cuarto Propio, 2001.

------- Escrituras de la diferencia sexual. Santiago de Chile: LOM, 1999.

ORTEGA, José. La estética neobarroca en la narrativa hispanoamericana. Madrid: José Porrúa Turanzas, 1984.

OSTROV, Andrea. "Las crónicas de Pedro Lemebel: un mapa de las diferencias", en La fugitiva contemporaneidad. Celina Manzoni. Buenos Aires: Corregidor (2003): 99-119.

------ "Pedro Lemebel: biografía”. Letras: Proyecto Patrimonio. (2002): 1-7. May 19, $2002<$ http://www.letras.s5. com/lemebel1.htm>.

PERLONGHER, Néstor. Prosa plebeya. Ensayos 1980-1992 (1988). Buenos Aires: Colihue, 1992.

PINO, Angeles Mateo del. "Chile, una loca geografía o las crónicas de Pedro Lemebel”. Hispamérica. 27. 80 (1998): 17-28.

PLAZA ATENAS, Dino. "Lemebel o el salto de doble filo", en Revista Chilena de Literatura 54 (1999): 123-35.

RANDELL, John. Sexual Variations. Westport, Conn.: Technomic Publishing Company, 1976. 
RICHARD, Nelly. La insubordinación de los signos (cambio político, transformaciones culturales y poéticas de la crisis). Santiago de Chile: Cuarto Propio, 1994.

------- Residuos y metáforas (Ensayos de crítica cultural sobre el Chile de la Transición). Santiago de Chile: Cuarto Propio, 2001.

------- "Tres recursos de emergencia: las rebeldías populares, el desorden somático y la palabra extrema” (2004): 1-8. 15 de febrero, 2004

$<$ www.literateworld.com/spanish/2002/escritormes/sep/w01/left.html

RÍOS, Mónica A. "Chile es un gran pliegue barroco hacia el interior". (Entrevista con Francisco Casas). Una Vuelta. 20 abril, 2004. 17 junio, 2006. http://www.unavuelta.com/sobrelibros/Libros.php?id_cont=185

SARDUY, Severo. Ensayos generales sobre el barroco. México —Buenos Aires: Fondo de Cultura Económica, 1987.

------ La simulación. Caracas: Monte Avila, 1982.

------- "Writing/Transvestism." Modern Latin American Fiction. Ed. Harold Bloom. (Ed.) New York: Chelsea House, 1990.

SIFUENTES-JÁUREGUI, Ben. Transvestism, Masculinity and Latin American Literature. Genders Share Flesh. New York: Palgrave, 2002. 